\title{
Rebuild the Basement Tectonic Framework of the Western South China Sea
}

\author{
Changsong $\operatorname{Lin}^{1}$ and Lihong Zhao ${ }^{2^{*}}$ \\ ${ }^{1}$ Key Laboratory of Submarine Geosciences of the Second Institute of \\ Oceanography, Hangzhou, 310012, China \\ linchs@126.com \\ ${ }^{2 *}$ Shandong University of Science and Technology, Qingdao, 266590, China \\ zhaolih@sina.com
}

\begin{abstract}
The west margin fault zone of the South China Sea is a tensional basement fault in the extended segment of the Indosinian Subplate toward the sea. It originally formed in the Mesozoic, and reactivated and developed further in the Cenozoic. It is not appropriate to regard this fault as a regional tectonic line between the Indosinian Subplate and the South China Sea Subplate because it does not exhibit the basic features of a regional boundary fault. A zone of gravity and magnetic anomalies in the southwest subbasin of the South China Sea extends westwards to the Zhongjian Island-Guangya Reef arcuate fault zone, and is the real regional tectonic line between the Indosinian Subplate and South China Sea Subplate. The formation of this basement tectonic framework might be closely associated with tectonic evolution of the ancient arc-trench system from the Proterozoic to the Mesozoic. The major faults are the south margin fault zone of the Qiongdongnan-Shenhu-Dongsha massif, the Red River fault zone, and the Zhongjian Island-Guangya Reef arcuate fault zone, which construct the basement tectonic framework of the South China Subplate, the Indosinian Subplate, and the South China Sea Subplate, and control the development and evolution of basement tectonics.
\end{abstract}

Keywords: the Western South China Sea; Geophysical feature; West margin fault zone of the South China Sea; Basement tectonic framework

\section{Introduction}

The western South China Sea (west of $114^{\circ} \mathrm{E}$ ) is the area where the deep-sea basin of the South China Sea meets the Indosinian Subplate and the southwestern South China block. Knowledge of the basement tectonic framework is important for understanding the regional tectonic status and function of the west margin fault zone of the South China Sea. This knowledge directly affects recognition and understanding of the regional tectonic evolution of the Indosinian Subplate and the South China Sea Subplate. Furthermore, the knowledge helps to understand the formation and evolution of oil- and gas-bearing basins and in the production and preservation of the oil and gas resources in the South China Sea.

This paper systematically analyzes the geophysical features of the western South China Sea and studies the regional tectonic status and function of the west margin fault zone of the South China Sea and the coupling relationship between the South China Sea Subplate and the Indosinian Subplate using improved geological and geophysical data from the South China Sea and its surroundings in combination with previous results to elucidate the basement tectonic framework of the western South China Sea. 


\section{Regional Geology of the Indosinian Subplate and the South China Sea Subplate}

It is necessary to understand the formation and the basic geology of the basement of the Indosinian Subplate and the South China Sea Subplate to define the basement tectonic framework of the western South China Sea.

\subsection{The Indosinian Subplate}

The Indosinian Subplate includes the Kontum massif and the Sunda block in the center of the Kontum cratonic uplift, which developed in the Early Proterozoic, and the basement of Proterozoic strata crops out extensively. The U-Pb isochron age of the basement metamorphic rock series is $2300 \mathrm{Ma}$. The accretion boundaries are made up of structural belts formed from the middle and late Paleozoic. Devonian -lower Carboniferous strata is distributed over almost the entire region, and are unconformable on the basement [1-2]. The age of the basement metamorphic rock series in the Indosinian Subplate is similar to that of the South China Subplate. The Sm-Nd isochron age of the oldest crystalline basement rocks in the South China Subplate is $2682 \pm 148$ Ma [1]. The Indosinian Subplate arches out toward the South China Sea, which implicates the general situation of the east side of the Kontum massif. This is similar to the South China Subplate arching out toward the East China Sea and the South China Sea.

The tectonic activity of the Indosinian plate has been very high in geological history, and its strata have been strongly transformed. The tectonic activity was controlled by the NE- and NW-striking basement faults. North Vietnam on the north side of Kontum massif is adjacent to the South China Subplate, which is bounded by the Chang Mountain, the Ma River, the Heishui River, and the Red River tectonic belt that trends NW from south to north. The basement rock of the Indosinian Subplate is a Precambrian complex.

The Sunda Shelf is located in the extended segment of the SE side of the Indosinian Subplate. The basement tectonic direction in this area is mainly toward the NE and NW, but the general tectonic framework is controlled by NE-trending faults. Mesozoic granite, granodiorite, porphyrite, and their weathered products make up the basement of the Mekong basin, which originated sometime in the Middle Jurassic-Early Cretaceous period [2]. Tectonic activity in the Sunda Shelf was strong and magmatic activity often occurred during the Mesozoic.

\subsection{The South China Sea Subplate}

Substantial geophysical and drilling data have provided information on the geological characteristics of the South China Sea Subplate. The western and southern parts are continental crust, while the southeastern part of the Dongsha massif might still retain residual oceanic crust from the Mesozoic [1]. The middle subbasin and the southwest basin are oceanic crust, which might have been established in Pre-Cenozoic and reactivated in the Cenozoic [3]. The whole South China Sea Subplate has very complex basement tectonics. There are several tectonic systems present, including NE-, NW-, $\mathrm{SN}-$, and EW-trending. The NE- and NW-trending tectonic systems are the most significant, and they form a checkerboard pattern [4]. This is also the basic tectonic framework of the South China Subplate that was created in the Precambrian and was fixed in the Mesozoic.

The following paragraphs summarize important information about the western and northern parts of the South China Sea Subplate. The basement of the South China Sea 
Subplate was established in the Late Proterozoic or the Precambrian. For example, granite gneiss and biotite monzonitic gneiss were found at $1251 \mathrm{~m}$ depth in the Xiyong-1 boring, with ages of $1450 \mathrm{Ma}$ and $627 \mathrm{Ma}$ [2], respectively. Thus, the basement of the South China Sea Subplate has a long formation and development history, and is much younger than the basement of the Indosinian Subplate and the South China Subplate. Drilling studies [1] have revealed that the Yanshanian magmatite of the South China Sea Subplate is considerably developed and widely distributed. Most of the basement rocks of the Cenozoic basins in the South China Sea are composed of a widespread magmatite, which means the basement has been complicated to an extent by Yanshanian magmatism.

The Indosinian Subplate is very much similar to the South China Subplate in terms of tectonics, and both of them were established at an early stage. But there are many differences in their tectonic history, the development level, the crustal structure, and the intensity and characteristics of crustal activity between the Indosinian Subplate and the South China Sea Subplate, both of them have a NE- and NW-trending basic tectonic framework that developed in Pre-Cenozoic. This indicates that have both been subjected to the same regional tectonic stress field for a long time.

\section{Regional Tectonic Status and Mechanism of Formation and Evolution of the west margin fault zone of the South China Sea}

\subsection{General}

The west margin fault zone of the South China Sea can be also called the offshore fault of eastern Vietnam [5], the eastern Vietnam fault zone [6], the boundary fault of eastern Vietnam [7], or the coastal fault of eastern Vietnam [8]. It is located at the transition area between the shelf and the slope on the eastern Vietnam coast. This fault zone consists of a series of nearly NS-trending fractures, and it extends for more than $1000 \mathrm{~km}$. The fault zone starts south of Hainan Island near $17^{\circ} 30^{\prime} \mathrm{N}$, and the northern part between $17^{\circ} 30^{\prime} \mathrm{N}$ and $11^{\circ} 30^{\prime} \mathrm{N}$ is generally called the west margin fault zone of the South China Sea and the southern part is called the Wan'an fault zone. The Wan'an fault zone makes up the eastern boundary of the Wan'an Basin [9], and both of them are sometimes called the west margin fault zone of the South China Sea [10]. Most researchers link the formation and evolution of this fault zone with the spreading of the southwest subbasin. The establishment of the fault zone was thought to be during the Cenozoic spreading of the South China Sea. The fault zone underwent strong dextral strike-slip shear as a transfer accommodation zone [11-13].

\subsection{Recognition of the Tectonic Significance of Fault Zones}

Some significant recognition are obtained by analyzing systematically tectonic significance and formation mechanism of the west margin fault zone of the South China Sea according to its geophysical characteristics [14].

The west margin fault zone of the South China Sea is indicated by the presence of a high gravity anomaly belt (Figure 1). The high gravity anomaly belt reveals the presence of high-density rock, which is a result of large-scale granite invasion into fractures. There are large differences in density with respect to its surroundings. However, the fault zone was not visible in the geomagnetic field but hidden in the background field, which changes very slowly (Figure 2). Studies have indicated that only the first, fourth, and fifth period intrusive-rocks have non-magnetic properties in the Cenozoic and Mesozoic igneous rocks. Thus, it can be proved that the major fault in this fault zone is a 
basement fracture belt formed in the Mesozoic, possibly during the Late Mesozoic. Seismic section data have shown that the west margin fault zone of the South China Sea was activated in the Cenozoic and controlled the sedimentation in Cenozoic basins distributed along the fault zone and its surroundings.

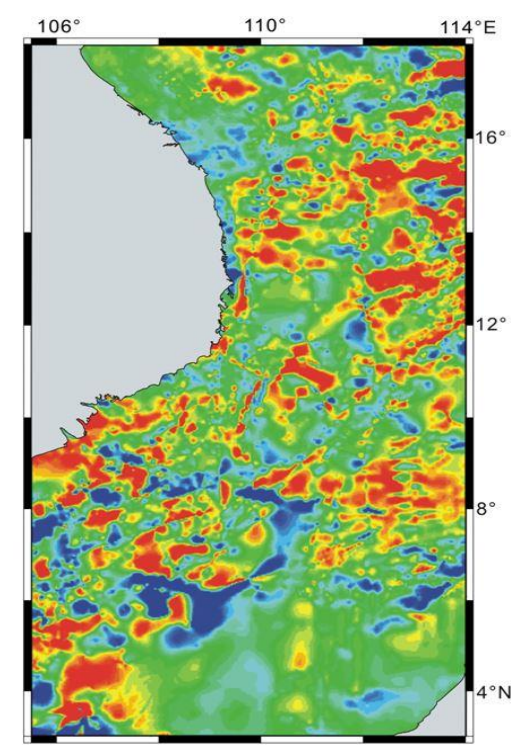

Figure 1. Free-air Gravity Anomaly of the Western South China Sea

It is possible that the east margin fault zone of the Wan'an basin between $8^{\circ} \mathrm{N}$ and $11^{\circ} 30^{\prime} \mathrm{N}$ is the southern extension of the west margin fault zone of the South China Sea and that the fracture in the middle of the Wan'an basin could be the east margin fault zone of the Wan'an basin according to previous seismic data. However, there are crucial differences in the interpretation of the tectonic geology between them. Research has shown that the large high-gravity anomalous bodies between $8^{\circ} \mathrm{N}$ and $10^{\circ} \mathrm{N}$ lie in the middle of the Wan'an basin, which means that the west margin fault zone of the South China Sea passes through the middle of the Wan'an basin, about 50-60 km from the east margin fracture zone of Wan'an basin, which was formed in the Cenozoic. However, the formation of the west margin fault zone of the South China Sea in the Mesozoic has not been detected directly by seismic means, and its formation is not yet completely understood. 


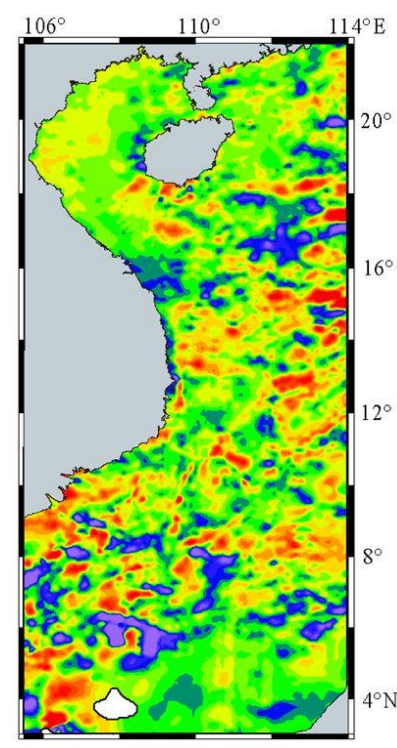

Figure 2. Geomagnetic Anomaly of the Western South China Sea

\subsection{The Regional Tectonic Line between the South China Sea Subplate and the Indosinian Subplate}

The basic characteristics of a regional boundary fault are as follows: it controls the tectonic evolution of the blocks on both sides for a long period on a fairly large scale, the geological and geophysical characteristics of the two blocks are significantly different (especially the gravity and magnetic fields), and the age of formation and trend should coordinate with the tectonic framework of the old block. For example, the south margin fault zone of the Qiongdongnan-Shenhu-Dongsha massif is a typical regional boundary fault developed between the South China Subplate and the South China Sea Subplate (Figure 3). The west margin fault zone of the South China Sea does not exhibit these features.

Although it is large, it was only a basement tensional fracture during the Mesozoic. Hence, there is a large difference in its age of formation compared with the basement of the Indosinian Subplate and the South China Sea Subplate, which formed in the Precambrian. Moreover, the basic tectonic framework and arc-shaped coast of the Indosinian Subplate took a long time to develop. The west margin fault zone of the South China Sea, which trends north-south, does not coordinate with the arc tectonic framework in the east margin of the Indosinian Subplate. It is clearly impossible that the former could have controlled the latter. Furthermore, the regional geophysical features (Figs.1 and 2) show that there are no apparent differences in the main characteristics of the gravitational and magnetic fields on each side of the fault zone. 


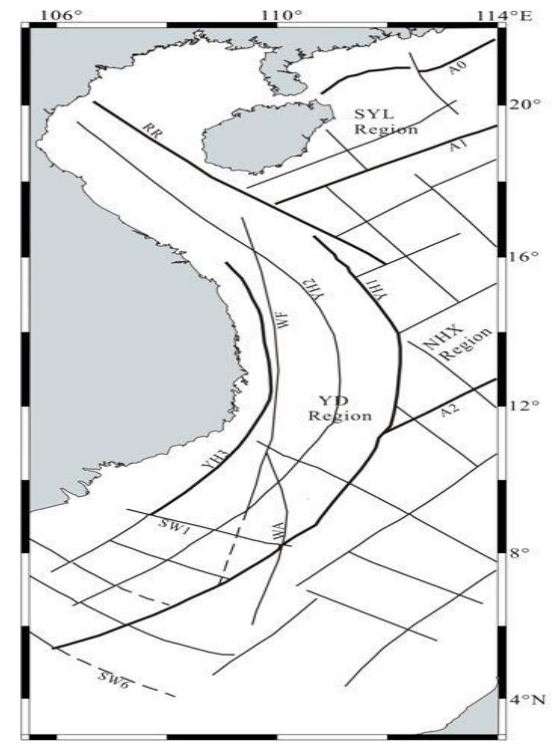

Figure 3. The Basement Fault Structures and Tectonic Zonation of the Western South China Sea

Thus, their basement properties are nearly the same, which means that the fault zone's impact on the basement was limited. Thus, the fault zone discussed here does not exhibit the essential characteristics of a regional boundary fault, and it is inappropriate to regard it as the regional tectonic line dividing the Indosinian Subplate from the South China Sea Subplate.

\subsection{Formation and Evolution of the Fault Zone}

Research has shown that the Pacific Plate generally moved northwards between the late Jurassic and the late Cretaceous, and the crust of eastern Asia was affected by a leftlateral strike-slip stress field, which resulted in a series of left-lateral oblique extensional faults $[4,15,16]$. Differential movement occurred between the Indosinian Subplate and the South China Sea Subplate under this stress field, and the west margin fault zone of the South China Sea formed along the eastern margin of the Indosinian Subplate where the crust was comparatively thin and weak.

Obvious changes have occurred in the crustal stress field of the eastern Asia since the early Cenozoic. The counterclockwise transtensional tectonic stress field was produced by the change in Pacific Plate movement from NNW to NW to NWW [4, 17, and 18]. The pattern of fault activity in East Asia has changed correspondingly. The NS-, NNE-, NE-, and NEE-trending faults have changed to dextral strike-slip activity. The crust was characterized by extensional subsidence in this period. The crust became extended toward the Pacific Ocean, which created extensional shear fracture and many basins restricted by them. They are called "rifting" by Ma Xingyuan and other geologists. The dextral strike-slip in the west margin fault zone of the South China Sea was an edge geological effect produced by the differential movement between the South China Sea Subplate and the Indosinian Subplate and the fault zone acted to regulate between them. The South China Sea Subplate simultaneously drifted toward the southeast and produced a series of extensional basins restricted by these fractures. 


\section{The Gravity and Magnetic Fields of the Western South China Sea}

The study area was divided into parts by analyzing the characteristics of the gravity and magnetic fields in the study region with geological and geophysical data of this region and its surroundings (Figure 1, Figure 2, and Figure 4). All these works have built foundations of the basement tectonic frameworks in the western South China Sea.

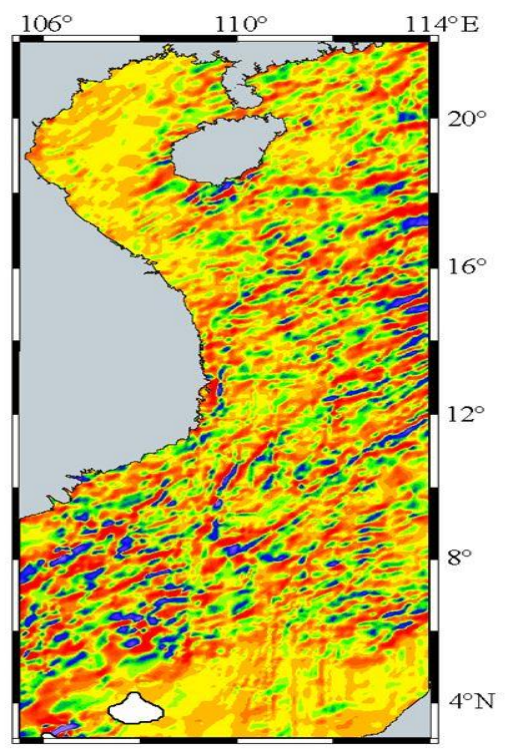

Figure 4. $135^{\circ}$ Directional of the Magnetic Field in the Western South China Sea

\subsection{Shenhu-Yitongansha, Beibu Gulf, and the Southeastern Leiqiong (SYL area)}

This region is part of the South China Subplate in terms of its tectonic location at the continental shelf of the northern South China Sea (Figure 3) characterized by a reducing and smoothly changing anomaly (Figures 1 and 2). The gravity background field is about 0 to $-25 \times 10^{-5} \mathrm{~m} / \mathrm{s}^{2}$, and local anomalies are comparatively less developed. The magnetic background field is from 0 to $-100 \mathrm{nT}$, while some local anomalies (from -100 to $-200 \mathrm{nT}$ and from 0 to $10 \mathrm{nT}$ ) are interspersed in this region. The gravity and magnetic background fields should reflect the presence of some deeply deposited non-magnetic and weakly magnetic Paleozoic epimetamorphic rocks, Mesozoic volcanic rocks, and granitoids. Local anomalies might reflect the presence of some magnetic and highdensity granitoids from the middle and late Mesozoic. Generally, the southwestern part of the gravity field including the Qiongdongnan basin and the northern Xisha trough, shows as a negative anomaly zone less than $-25 \times 10^{-5} \mathrm{~m} / \mathrm{s}^{2}$, which changes fairly slowly. The magnetic field shows as a reducing and slowly changing negative anomaly zone with a background field in the interval between 0 and $-50 \mathrm{nT}$, with some small and weak local anomalies, implying weak tectonic activity and that the basement settled deeply during thick sedimentation in the Cenozoic.

The gravity and magnetic anomalies of this region are generally NEE-trending, extending to the west and ending at the Red River fault zone (RR) toward the sea. The distinctive anomalies in this region extend toward the South China Sea and end at the southern margin fault zone of the Qiongdongnan-Shenhu-Dongsha massif (A1) combining with data of the east adjacent areas(Figures1, 2, and 3). 


\subsection{The Western South China Sea Basin (NHX Area)}

This area is located in the western South China Sea Subplate (Figure 3). The gravity and magnetic field patterns are complicated (Figures 1 and 2). The gravity background field is about 0 to $-25 \times 10^{-5} \mathrm{~m} / \mathrm{s}^{2}$ at the Zhongsha Islands and Xisha Islands in the north, while local anomalies from 0 to $50 \times 10^{-5} \mathrm{~m} / \mathrm{s}^{2}$. The magnetic background field is between 0 and $-100 \mathrm{nT}$ interspersed with many fairly local anomalies from-250 to 300 nT. The background field reflects the presence of Proterozoic and Paleozoic epimetamorphic basement. Some local anomalies are caused by Cenozoic multistage eruptions of volcanic rocks and the heterogeneous magnetic Yanshan high-density granitoid that hasintruded along fractures.

The gravity background field of the southwest subbasin in the south increases and its anomaly changes slowly from 0 to $25 \times 10^{-5} \mathrm{~m} / \mathrm{s}^{2}$ interspersed with a few local anomalies. The increased gravity background field might relate to uplift of the upper mantle. Another obvious characteristic of the gravity field is that a narrow-band NEstriking negative anomaly (from 0 to $-25 \times 10^{-5} \mathrm{~m} / \mathrm{s}^{2}$ ) is located in the middle of this zone. The regional geomagnetic field of the southwest subbasin is mainly a series of NEstriking striped anomalies characterized by alternate positive and negative variations. The formation mechanism of the magnetic anomalies of this area is generally thought to have been sea-floor spreading. However, there is no agreement on the mechanism, and at least eight mechanisms for the expansion between the early Cretaceous and the present have been put forward [4]. The gravity and magnetic anomaly zone of this area extends to the southwest and ends at the arc structure line of Zhongjian Island-Guangya Reef arcuate fault zone off east Vietnam (YH3) (Figs 1-4).

\subsection{Anomaly Area of Eastern Vietnam (YND Area)}

This area is located in the narrow band between the coastal arc fracture (YH1) and the arc structure line of the Zhongjian Island-Guangya Reef arcuate fault zone (YH3) off eastern Vietnam (Figure 3). It is $150-200 \mathrm{~km}$ wide and mainly parallel to the Vietnamese coast, which has a narrow northern part and a broad southern part. The anomaly areas off eastern Vietnam extend toward the north and end at the sea-ward extended segment of the NW-striking Red River fault zone (RR) and toward the southwest and end at the NW-striking SW6 fracture (Figure 3). This region can be roughly divided into a southern subregion and a northern subregion separated by the NW-striking Mekong estuary fault zone (SW1) (Figure 3), according to the features of the gravity and magnetic anomalies (Figures1 and 2).

The background gravity field of the northern subregion reduces because of the negative anomaly from about 0 to $-25 \times 10^{-5} \mathrm{~m} / \mathrm{s}^{2}$ and its local anomaly (from 0 to $50 \times$ $10^{-5} \mathrm{~m} / \mathrm{s}^{2}$ ) is developed considerably. The background magnetic field of the northern subregion reduces because of the negative anomaly from about 50 to $-100 \mathrm{nT}$. Hence, the variations are very small and relatively gradual and some small local anomalies are interspersed in this region. The background gravity field of the northern subregion rises from 0 to $25 \times 10^{-5} \mathrm{~m} / \mathrm{s}^{2}$, which is close to the west side of $110^{\circ} \mathrm{N}$. A very obvious NSstriking high-gravity narrow-band anomaly (from 0 to $50 \times 10^{-5} \mathrm{~m} / \mathrm{s}^{2}$ ) is developed near the area, which is about $10-20 \mathrm{~km}$ wide (Figure 1). There is a steep gradient change between this narrow band and the background field, which shows gravity anomaly protrusion. The narrow band is in some places divided by NW-striking anomaly zones, which extend intermittently and show segmented development. This type of gravity anomaly is characteristic of the west margin fault zone of the South China Sea. However, there is no magnetic anomaly corresponding to that shown by the gravity field along the fault zone (Figure 2). It is perhaps hidden by the background magnetic field. 
Geophysicists were not interested in this contradictory problem between gravity field and magnetic field.

The southern subregion is the Sunda shelf area, which is quite different compared to the northern subregion. The background gravity field rises from 0 to $25 \times 10^{-5} \mathrm{~m} / \mathrm{s}^{2}$, and its local anomaly (from 25 to $50 \times 10^{-5} \mathrm{~m} / \mathrm{s}^{2}$ ) is developed considerably. The background magnetic field is from 0 to $-50 \mathrm{nT}$, and its local anomaly (from 300 to $-500 \mathrm{nT}$ ) is very well developed. The magnetic field is rather complicated and the magnetic anomaly trends in different directions i.e., NE, NW, NWW, and NS direction. However, it is mainly controlled by NE- and NW-striking tectonic zones.

The differences between these two subregions are obvious. The basement of the north subregion developed some Cenozoic basins during deep rifting, including the Qui Nhon Basin, the China and Vietnam Basin, and the Wan'an Basin. The tectonic activity of the northern subregion is relatively weak and some local anomalies are mainly caused by the Yanshanian granitoids. The Sunda shelf basement of the southern subregion is relatively uplifted, and its tectonic activity is relatively strong. Local anomalies are caused by Mesozoic granitoids and Cenozoic basic and ultrabasic rocks that invaded the basement faults.

The coastal magnetic field of the Indosinian Subplate behaves as a gradient transition toward the sea, according to the CCOP geomagnetic data. This feature indicates that the basement of the eastern Vietnam anomaly zone is similar to the lithofacies of the Kontum massif, which is possibly composed of weakly magnetic metamorphic rocks from Precambrian or Paleozoic. The background magnetic field is mainly caused by these rock units.

\section{Reconstruction of the Regional Tectonic Framework}

The regional tectonic framework between the South China Sea Subplate and the Indosinian Subplate described in this paper is different from the previous reports. The fracture is the result of crustal rupture caused by ground stress. It will be reflected in the gravity and magnetic fields if magnetic rocks fracture, dynamic metamorphism occurs, or magmatism occurs along the fault. Morevoer, the regional basal fault can be determined by a significant difference in the gravity and magnetic fields between the two sides of different sections, or a notable interruption in the tectonic zone.

\subsection{Distribution of Basement Faults}

The distribution of the basement faults in the study area and their tectonism is revealed from the gravity and magnetic field data (Figure 1 and 2) and their associated map (Figure 4) in combination with regional geological data and some seismic data. Many faults are developed in the area (Figure 3), mainly NE-striking, NW-striking, and arc fractures according to their trend and shape.

5.1.1. NE-striking Faults: The main tectonic line trends toward the northeast, as can be seen in the regional distribution of the gravity and magnetic fields. These faults were formed in the pre-Mesozoic and successively developed in the Mesozoic and Cenozoic, which form the basic tectonic framework of the South China Sea. The faults have been truncated or destroyed by NW-striking and arc tectonic lines. NE-striking faults are well developed in the South China Sea (Figure 3). They extend far along $45^{\circ}$ and fault strongly. Some fractures became the boundaries of large regional structures (such as A1), and mainly control the lithofacies, magmatism, sedimentation, and tectonic 
development of the two blocks. This set of long active faults is generally transtensional, and they mainly developed in the pre-Mesozoic and were active for a long time.

a. Dongshan Island-Hong Kong-Haikou Coastal Fracture (A0): It basically extends parallel to the Fujian and Guangdong coastlines of the South China Subplate, offset by NW-striking faults. It is an important fracture between the Fujian and Guangdong coastal and continental shelves, and controls the regional tectonics.

b. The Southern Margin Fault of the Qiongdongnan-Shenhu-Dongsha Massif (A1): It is located at the south edge of the continental shelf of the South China Subplate. On its north side, the Dongsha massif extends toward the NE to the Beigang uplift of western Taiwan, and SW to the Shenhu-Yitong massif through the Panyu low uplift. The southern margin fault of the Qiongdongnan-Shenhu-Dongsha massif is an important regional tectonic boundary, the north side of which is continental shelf and the south side is a low continental slope with a regular magnetic field and a decreasing gravitational field. Both sides of the fracture have different gravity and magnetic field features. The fracture plays an important role in controlling the tectonic development of its two sides. The fracture, which extends toward the SW from southern Yitongansha to southeastern Qiongdao, appears to be the southwest extension of the A1 fracture from the gravity data, but the geomagnetic field shows that their activities and functions are different.

c. The Fracture in Middle of the Southwest Basin of the South China Sea (A2): It appears as a NE-striking narrow-band low magnetic anomaly in this fracture, which also has a distinctive negative gravity anomaly. It is an important basement fault in the Southwest Basin area.

5.1.2. NW-striking Faults: NW-striking basement faults are generally transpressive faults distributed through the whole South China Sea (Fig.3). Magmatism has occurred rarely along these fractures. Many of the fractures distinctly cut off and warp the gravity and magnetic anomalies and the NE-, NEE-, or nearly NS-trending tectonic strips. They were formed before the Mesozoic and developed in the Mesozoic and Cenozoic. They form a checkerboard pattern basement tectonic framework in the South China Sea together with the NE-trending faults.

The most important fault of the study area is the extension of the Red River fault zone (RR) in the sea. On land, this zone constitutes a geological and geomorphological boundary separating the South China Sea Subplate from the Indosinian Subplate with the Chang Mountain, Ma River, and Heishui River tectonic belts, all of which are NWtrending. The Red River fault zone is a large long-term shear slip active zone that developed in the Precambrian. The fault zone meets the sea at the mouth of the Red River, and extends to the southeast along the Yinggehai Basin through the entire South China Sea [1]. Although the two are in the same line, they may have different structural dynamic significances.

Another important fault is the Mekong river mouth fault zone (SW1), which extends toward the southeast from the mouth of the Mekong River to the Zhongjian IslandGuangya Reef arcuate fault zone of eastern Vietnam (YH3) (Fig.3). The arc tectonic zone of eastern Vietnam is divided into southern and northern subregions.

A group of NWW- to NW-trending fractures have developed in the sea from the Sunda Block - Natuna Island shelf to the Singapore Submarine Plateau, which is located in southeastern Vietnam in the South China Sea. Extensive magmatism has occurred widely along the fractures, which shows that they belong to tensional fractures. They 
extend toward the SE off the Zhongjian island-Guangya Reef arcuate fault zone (YH3). This shows that there are great differences in regional tectonics and crustal background stress fields between these and the NW-trending fractures in another area of the South China Sea. SW6 is one of these tectonic lines. The south side of SW6 is a NW-trending narrow-band negative magnetic anomaly that corresponds to the Maliao Basin. It has a deep basement. It meets the NW-trending Malaya Island tectonic zone toward the SW.

5.1.3. The Arc Fault Zone of Eastern Vietnam: There are three conspicuous and important arc faults (YH1, YH2, and YH3) in the sea off eastern Vietnam. They intermittently extend over $1400 \mathrm{~km}$ parallel to the coastline of eastern Vietnam. The most important fault is the Zhongjian Island-Guangya Reef arcuate fault (YH3). It is located at the west margin of the southwest subbasin of the South China Sea. It is almost parallel to the coastline of Vietnam at a distance of $200 \mathrm{~km}$. It extends SW to Natuna Island, and ends at the SW6 Fracture. It extends NW to the southwest of Hainan Island, and intersects with the SE-striking extension of the Red River fault zone, which goes into the sea. Strong faulting and magmatism have caused prominent local anomalies along the fracture and its vicinity. The South China Sea Subplate lies at the east side of the fault zone. Both sides have apparently different gravitational and magnetic fields. The NE-striking tectonic line extends SW toward the South China Sea. There is no doubt that this fault zone plays a very important role in controlling the development of the regional tectonics of each side, which began in the Precambrian. This fault zone is the real regional tectonic line dividing the Indosinian Subplate and the South China Sea Subplate. Its tectonism is similar to that of the southern fault zone of the QiongdongnanShenhu-Dongsha massif (A1).

Another important coastal fault off eastern Vietnam (YH1) extends in an arc close to the coastline of Vietnam. It is similar to the coastal fault of Dongshan Island-Hong Kong-Haikou in its tectonics in the South China Subplate. It is a significant regional boundary between continental anomalies and continental shelf sea anomalies, and plays an important role in controlling regional tectonics. There is an arc fault (YH2) between the two faults above and parallel to them, which intersects with the southwest margin fracture of the Yinggehai Basin towards the NW. Although it is not a regional fracture but it is an important fracture, because it distinctly controls a series of Cenozoic basins including the Yinggehai Basin, the Guiren Basin, the Zhongyue Basin, the Wan'an Basin, and the Kunlun Basin.

\subsection{The Dynamic Mechanism of Development and Evolution of the Regional Tectonic Framework}

The geology of the Pacific Ocean and Eurasia are representative of the whole Earth. Studies of the circum-Pacific tectonic belt have indicated that the motion of the Pacific Ocean plate did not begin in the Mesozoic, and the history of the ancient Pacific can be traced back to the Proterozoic [19]. Research in geotectonics, paleomagnetism, paleontology, and paleoclimatology [20-22] has shown that the Eurasian Plate experienced long-term oceanic continental crust evolution and multi-plate dynamic change processes from the Paleozoic to the Mesozoic eras. It is obvious that lateral accretion of continental crust leads to continuous contraction of oceanic crust and further accretion of continental crust.

Oceanic crust has been transformed to continental crust that has lasted for billions of years, and this crust has been in the center of Siberia since the Archean. The North China Plate, the Tarim Plate, and the South China Subplate have all experienced the transition from ocean to continent and the process of cratonization. These plates 
continuously moved and accreted toward Siberia as the Paleo-Asian Ocean and the Paleo-Tethys Ocean gradually subducted. The Indian Plate, the Arabian Plate, the Iran microplate, and the Afghan microplate split from Pangaea and moved toward and accreted with the Siberian Plate, to finally form the huge Eurasian Plate. This dynamic process was apparently driven by the global crust stress field. Plate movement tracks show that the stress field vector (NW) points to Siberia. The checkerboard tectonic framework in East Asia, which is made up of NE- and NW-trending fractures, is the geological response to this crustal stress field.

As previously mentioned, the developmental history of the South China Subplate and the Indosinian Subplate began earlier than that of the South China Sea Subplate. The curved edges of the former two plates bow out of the Pacific and their tectonic evolution was also controlled by the large curving fault. The pattern of the basement tectonic framework might be closely related to the tectonic evolution of the ancient arc-trench system; hence, the South China Subplate and the Indosinian Subplate might have been experiencing evolution of the arc-trench system from the Proterozoic to the Mesozoic. The south margin fault zone of the Qiongdongnan-Shenhu-Dongsha massif (A1) and the arc fault zone of the Zhongjian Island-Guangya Reef arcuate fault zone (YH3) are two ancient subduction zones below which the South China Sea Subplate subducted toward the NW. The Red River fault zone (RR) has generally played a transform fault role in the differential motion of these two plates. The relationship of the South China Subplate and the Indosinian Subplate may be analogous to the Honshu and the Ryukyu arc-trench system in Japan.

\section{Conclusions}

The following conclusions can be obtained from the studies of the gravitational and magnetic fields and the tectonic characteristics of the western South China Sea Subplate.

1) The west margin fault zone of the South China Sea is a basal tensile fracture in the extension of the Indosinian Subplate toward the sea, which was created in the Mesozoic and developed successively in the Cenozoic. It is nearly NS-trending, which does not agree with the arc basement tectonic framework in the east margin of the Indosinian Subplate. There are no apparent differences in the gravity and magnetic fields on either side of the fault zone, which means that its impact on the basement is limited. Thus, it is impossible that this fault zone controlled the development of basement tectonics in the Proterozoic. The west margin fault zone of the South China Sea does not show the basic features of a regional boundary fault, so it is inappropriate to regard it as the tectonic line between the Indosinian Subplate and the South China Sea Subplate.

2) There are distinct differences in the gravity and magnetic fields on each side of the south margin fault zone of the Qiongdongnan-Shenhu-Dongsha massif (A1). It plays an important role in controlling the tectonic development of each side. It is the crucial regional tectonic line between the South China Subplate and the South China Sea Subplate.

3) The Red River fault zone is a huge continuous strike-slip shear zone, which was created in the Precambrian. It goes into the sea at the mouth of the Red River and then extends toward SE along the Yinggehai Basin in the sea. It is the regional boundary between the South China Subplate and the Indonisian Subplate.

4) The Zhongjian Island-Guangya Reef arcuate fault zone is coherent with tectonics on the east side of the Indonisian Subplate parallel to coastline. There are obvious differences in the gravitational and magnetic fields of each side. Furthermore, the NE-trending fault belts of the South China Sea extend toward the SW and end at 
this tectonic line. Thus, this fault zone plays a very important role in controlling the development of each side. It was created in the Precambrian. This fault zone is the real regional tectonic line between the Indonisian Subplate and the South China Sea Subplate.

The formation of the basement tectonic framework in the study area might have a close relationship to the arc-trench systems from the Proterozoic to the Mesozoic. The major fault is composed of the south margin fault zone of the Qiongdongnan-ShenhuDongsha massif, the Red River fault zone, and the Zhongjian Island-Guangya Reef arcuate fault zone. They constitute the basic basement tectonic framework of the South China Subplate, the Indosinian Subplate, and the South China Sea Subplate. They control the development and evolution of the basement tectonic framework among them.

\section{Acknowledgements}

This work was sponsored by the National Natural Science Foundation of China(Grant No. 41106037) and the Key Laboratory of Marine Surveying and Mapping in Universities of Shandong (Shandong University of Science and Technology)(Grant No. 2013B06).

\section{References}

[1] J. W. Wan, H. T. Zhang, H. C. Zhang, "The memoir of the special item surveys of the exclusive economic area and continental shelf of China, Ocean Press", Beijing (2002), pp. 184-197.

[2] Z. C. Che, L. Liu and J. H. Luo, "The tectonics of China and adjacent regions", Science press, Beijing (2002), pp. 437-478.

[3] C. S. Lin, X. J. Yu and Y. H. He, "Question on the spreading of the South China Sea basin", Acta Oceanologica Sinica, vol. 28, no. 1, (2006), pp. 67-76.

[4] C. S. Lin, Y. Tang and Y. H. Tan, "Geodynamic mechanism of dextralslip of the western-edge faults of the South China Sea", Acta Oceanologica Sinica, vol. 31, no. 1, (2009), pp. 159-167.

[5] W. Y. Zhang, Y. K. Li and Z. S. Liu, "Marine and continental geotectonics of China and its environs Science Press, Beijing (1986), pp. 344-356.

[6] B. C. Yao, W. J. Zeng and D. E. Hayes, "The geological memoir of South China Sea jointly by China and USA", China University of Geoscience Press, Wuhan (1994), pp. 184-194.

[7] T. Y. Lee and L. A. Lawver, "Cenozoic plate reconstruction of Southeast Asia", Tectonophysics, vol. 251, no. 1-4, (1995), pp. 85-138.

[8] G. D. Chen, "Crustobody geotectonics of Asian continent and adjacent seas", Hunan Education Press, Changsha, (1998), pp. 270-273

[9] L. T. Sun, W. H. Zhan and Z. X. Sun, "Study on the activity of the western margin faults of South China Sea", Marine Science Bulletin, vol. 24, no. 3, (2005), pp. 42-47.

[10] L. Wan, B. C. Yao, and Y. Wu, "Cenozoic geological characteristics in the west of the South China Sea”, Marine Geology \& Quaternary Geology, vol. 25, no. 2, (2005), pp. 45-52.

[11] D. E. Hayes, "The Tectonic and Geologic Evolution of Southeast Asian Seas and Islands, Part 2", Am Geophys Union, Geophysical Monograph, vol. 23, (1980), pp. 89-104; Washington, DC, America.

[12] N. H. Hollowaw, "North Palawan block, Philippines-its relation to Asian mainland and role in evolution of South China Sea", AAPG, no. 66, (1982), pp. 1355-1383.

[13] L. Wan, B. C. Yao and N. Y. Wu, "The extending of Red River Faults in the South China Sea and its tectonic significance", China University of Geoscience Press, Wuhan (2000), pp. 22-32.

[14] C. S. Lin, J. Y. Gao and L. H. Zhao, "Geophysical features of the western-edge fault zone of the South China Sea and its significance of tectonic geology", Acta Oceanologica Sinica, vol. 31, no. 2, (2009), pp. 98-103.

[15] W. S. Hu, B. Q. Lv and D. Y. Guan, "Characteristics of Tan-Lu Fault zone and Development of Mesozoic and Cenozoic basins along it", Marine Geology \& Quaternary Geology, vol. 23, no. 4, (2003), pp. 51- 58.

[16] G. Zhu, C. Z. Song and D. X. Wang, "Study on strike-slip 40Ar/39Ar geochronology and tectonic significance of Tanlu Fault zone”, Science in China (series D), vol. 31, no. 3, (2001), pp. 250-256.

[17] E. D. Jackson, H. R. Shaw and K. E. Baggar, "Calculated geochronology and stress field orientation along the Hawiian Chain”, Earth and Planet Sci. Lett., no. 26, (1975), pp. 145-155. 
[18] C. S. Lin, F. Y. Chu and J. Y. Gao, "On tectonic movements in the South China Sea during the Cenozoic", Acta Oceanologica Sinica, vol. 28, no. 1, (2009), pp. 25-36.

[19] X. C. Jin, "Plate tectonics basis", Shanghai Science and Technology Press, Shanghai (1984).

[20] J. S. Ren, T. Y. Chen and B. G. Niu, "Tectonic evolution of the continental lithosphere and metallogeny in eastern China and adjacent areas", Science Press, Beijing (1990).

[21] S. J. Li, W. J. Zhang and M. S. Geng, "Geological features of Mongolia Arc structure and its formation and evolution", Geological Publishing Press, Beijing (1998).

[22] X. Chen, Y. P. Ruan and A. J. Boucot, "China Paleozoic climate change", Science Press, Beijing (2001).

\section{Authors}
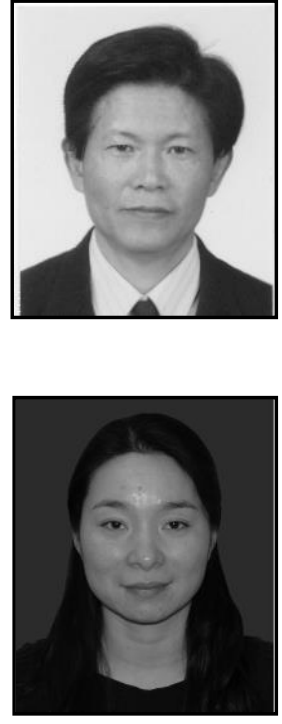

Lihong Zhao, She received his B.S. and M.S. degree in application geophysics from Ocean University of China in 1999 and 2002, China, Ph. D degree in marine geology from Institute of Oceanology, Chinese Academy of Science, China, in 2005, respectively. She is now the associate professor in college of Earth Science and Engineering, Shandong University of Science and Technology, Qingdao, China. Her main research interests are Marine Geophysics and Tectonics. 